\title{
DESAFIOS À SUSTENTABILIDADE EM UMA INSTITUIÇÃO DE ENSINO SUPERIOR NA BAHIA
}

\section{CHALLENGES TO SUSTAINABILITY IN A HIGHER EDUCATION INSTITUTION IN BAHIA}

\section{Renato de Almeida}

Doutor em Ciências (Oceanografia Biológica), Universidade de São Paulo. Universidade Federal do Recôncavo da Bahia / Centro de Ciências Agrárias, Ambientais e Biológicas. (renato.almeida.ufrb@gmail.com)

\section{Thaisa Teixeira De Souza}

Graduanda em Engenharia Agronômica, Universidade Federal do Recôncavo da Bahia. Bolsista do PET Mata Atlântica/UFRB. (teixeira.thaisa098@gmail.com)

\section{Ariel Santiago Da Silva Galvão}

Graduando em Engenharia Sanitária e Ambiental, Universidade Federal do Recôncavo da Bahia. Bolsista do PET Mata Atlântica/UFRB. (ariel santiag0@hotmail.com)

\section{Matheus Ribeiro De Jesus Cerqueira}

Graduando em Engenharia Sanitária e Ambiental, Universidade Federal do Recôncavo da Bahia. Bolsista do PET Mata Atlântica/UFRB. (matheus15 ribeiro@hotmail.com)

\section{Naiane Dos Santos Da Silva}

Graduanda em Agroecologia, Universidade Federal do Recôncavo da Bahia. Bolsista do PET Mata Atlântica/UFRB. (nai7x70@gmail.com)

\section{Resumo}

Uma Universidade Sustentável desenvolve ações nas diferentes dimensões da sustentabilidade, assumindo um sistema de gestão ambiental na própria instituição e contribuindo para a formação de jovens com pensamento crítico. Adotou-se a análise de conteúdo, para abordar a evolução histórica da preocupação ambiental em três diferentes versões do Plano de Desenvolvimento Institucional de uma Instituição de Ensino Superior (IES) na Bahia, e efetuaram-se apontamentos sobre o estágio de sustentabilidade da IES. Hoje, a sustentabilidade na sede da universidade reflete processo histórico associado à sua origem e estratégia da multicampia. Esforços induziram os primeiros projetos coletivos, mas sem uma continuidade de longo prazo e metas quantificáveis, prevalecendo ações individuais e pontuais. A adoção dos Objetivos do Desenvolvimento Sustentável 2030 contribuiria ao enfrentamento dos desafios que se apresentam para a sustentabilidade universitária.

Palavras-chave: Universidade, Educação Ambiental, Ambientalização.

\section{Abstract}

A Sustainable University develops actions in the different dimensions of sustainability, assuming an environmental management system in the institution itself and contributing to the formation of critical thinking for young people. Content analysis was chosen to discuss the historical evolution of environmental concern in three different versions of the Institutional Development Plan of a Higher Education Institution (HEI) in the state of Bahia, as well as notes on the sustainability stage of HEl. Currently, sustainability on the university's campus reflects the historical process associated with its origin and multicamp strategy. Efforts induced the first collective projects, but without a long-term continuity and quantifiable goals, individual and specific actions prevailing. The use of the Sustainable Development Objectives 2030 would help to face the challenges that are presented for university sustainability.

Keywords: University, Environmental Education, Greening. 


\section{INTRODUÇÃO}

A ambientalização é um processo em discussão dentro do ensino formal, que vai muito além da abordagem curricular ou das práticas de ensino. Neste trabalho, adotamos a concepção sistêmica, em que a ambientalização não está restrita às mudanças de conteúdos, metodologias, materiais ou atividades; pois também abrange mudanças na estrutura organizacional, na capacitação ambiental dos docentes, na avaliação de processos educativos e seus resultados, além de mudanças institucionais na infraestrutura e normas de funcionamento (KITZMANN; ASMUS, 2012). De qualquer forma, a ambientalização busca uma aproximação do ensino formal aos preceitos de sustentabilidade ambiental.

No Brasil, a preocupação com a sustentabilidade nas instituições de ensino nasce em diferentes momentos e com diferentes motivações.

Em 2003, ações interministeriais induziram a realização das Conferências Nacionais Infantojuvenis de Meio Ambiente (CNIJMA), incluindo a formação das Comissões de Meio Ambiente e Qualidade de Vida (COMVIDAS), especialmente nas escolas do ensino fundamental. Em 2009, essas ações foram agrupadas em torno do Programa Nacional Escolas Sustentáveis, com o propósito de apoiar processos formativos para a transição das escolas para a sustentabilidade socioambiental. O documento oficial do programa somente foi lançado em 2012, mas foi a Resolução CD/FNDE/MEC nำ18/2013 (MEC, 2013) que apresentou o "Manual Escolas Sustentáveis" e as diferentes dimensões interrelacionadas, para se alcançar a sustentabilidade no espaço escolar: gestão, currículo e espaço físico. O suporte financeiro dessas ações apenas se efetivou com a Resolução CD/FNDE/MEC no18/2014 (MEC, 2014).

No Ensino Superior, foi diferente. Já em 1986, a Secretaria Especial de Meio Ambiente convocou os seminários nacionais "Universidade e Meio Ambiente", que serviram de espaço aos debates sobre práticas de pesquisa e ensino relacionadas à temática ambiental no contexto das Instituições de Ensino Superior (IES) (OLIVEIRA et al., 2007). Mas, foi a Agenda 21, principal contribuição documental da Conferência Rio-92, que trouxe recomendações à promoção do desenvolvimento em termos de progresso social, econômico e ambiental, conclamando todos a uma participação efetiva na busca de resultados reais. E assim, logo se defendeu as Universidades enquanto excelentes candidatas a dar exemplo de como criar as bases desse novo desenvolvimento. Isso gerou pressão nas Instituições de Ensino Superior (IES) para fomentarem um desenvolvimento baseado na sustentabilidade. As Universidades, com o seu papel transformador e educador, contribuiriam com modelos para a formação do pensamento sustentável crítico, adotando medidas para um sistema de gestão ambiental da própria instituição, bem como a incorporação de conceitos inovadores para a disseminação da consciência sustentável entre docentes, discentes e toda a comunidade acadêmica (LARA, 2012).

Superadas mais de duas décadas, a sustentabilidade nas IES já não deve ser encarada como uma "inovação radical", mas presente nas universidades por demandas de diferentes origens (pressões internas e externas), iniciativas individuais e coletivas, mas também induzidas pelo corpo diretivo (BIZERRIL; ROSA; CARVALHO, 2016). Também há consenso de que as universidades são estratégicas na promoção da sustentabilidade, incluindo a redução dos impactos de suas próprias atividades, a promoção da inovação, a formação de líderes, professores e profissionais que influenciam a sociedade, além da sua ação no desenvolvimento regional (BIZERRIL et al., 2018).

Historicamente, o conceito "Universidades Sustentáveis" foi paulatinamente construído a partir de um sistema multidimensional. A representação esquemática (Figura 1) e a descrição dessas diferentes dimensões necessárias à análise do desempenho da sustentabilidade nas IES (Quadro 1) foram apresentadas por Lozano et al. (2015) e Bizerril et al. (2018).

O presente estudo teve por objetivo geral conduzir esforço analítico documental para acompanhar a preocupação ambiental em uma IES Federal na Bahia, adotando as diferentes dimensões para analisar o atual desempenho da sustentabilidade universitária e oferecer um panorama inicial, referencial, aos esforços conduzidos pela IES até o presente.

É válido destacar que a IES em análise é fruto de uma política de interiorização do ensino superior, criada em 2005, no sistema de multicampia. Sua atual sede aproveitou grande 
parte da infraestrutura da antiga Escola Agrícola da Bahia, iniciada em 1943. Atualmente, essa IES conta com 45 cursos de graduação em seis diferentes campi. Ao todo, são mais de 12.345 matrículas na graduação, 598 ingressos na pósgraduação, 834 docentes e 711 técnicos administrativos. Esse crescimento vertiginoso impõe desafios ambientais cotidianos à universidade, demandando ações de planejamento e manutenção que se apresentam com forte preocupação da comunidade acadêmica.

\section{Figura 1: Sistema Universitário usado para analisar o desempenho da sustentabilidade}

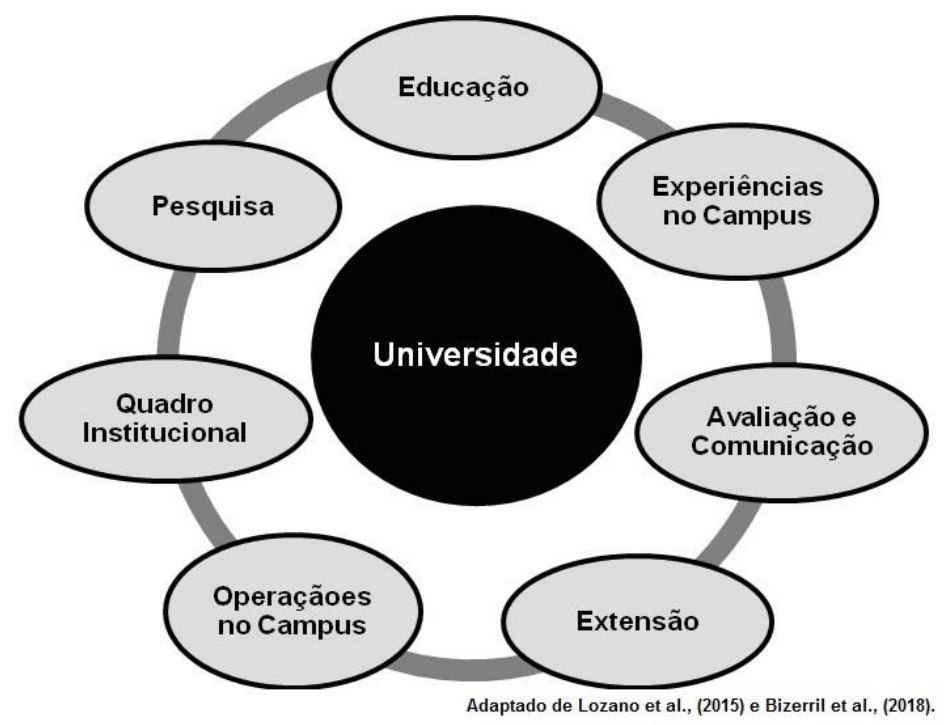

Fonte: Adaptada de Lozano et al. (2015) e Bizerril et al. (2018).

Foram analisadas, inicialmente, as três versões consecutivas do Plano de Desenvolvimento Institucional (PDI). É o PDI que fornece informações sobre parte dos compromissos com a sustentabilidade ambiental, além da organização e planejamento da gestão acadêmica e administrativa das universidades federais brasileiras, influenciando a melhoria da qualidade do ensino; a uniformidade das tarefas administrativas; a gestão financeira eficiente; o investimento em infraestrutura; entre outros (DAL MAGRO; RAUSCH, 2012). Então, de alguma forma, espera-se que o PDI possa expressar aspectos das diferentes dimensões de uma Universidade Sustentável, além de outros documentos oficiais, relatórios de gestão e conhecimento acadêmico fruto das ações de pesquisa, ensino e extensão.

De forma complementar, foram sistematizadas as informações colhidas em um projeto de extensão desenvolvido no âmbito do Programa de Educação Tutorial (PET) e coordenado pelo grupo PET Mata Atlântica: conservação e desenvolvimento. $O$ projeto envolveu um ciclo de debates destinado a discutir, junto à comunidade acadêmica, os principais problemas ambientais existentes no campus Sede da IES e seu entorno imediato, de modo a fomentar ações e interesses pela sustentabilidade e pela gestão ambiental na universidade.

A interpretação do conjunto de ações e dos resultados observados no Relatório de Gestão institucional foi confrontada com descritores de diferentes estágios da sustentabilidade ambiental em uma instituição universitária, tendo sido adotado o Auditing Instrument for Sustainability in Higher Education (AISHE) desenvolvido pela Fundação Europeia de Gestão da Qualidade (ROORDA, 2001).

Em linhas gerais, trata-se de um método de auditoria, além de um instrumento que pode ajudar a formular políticas. Foi, inicialmente, composto por indicadores baseados no ciclo PDCA (planejar, fazer, verificar e agir), facilitando a compreensão de uma determinada situação e possibilitando a comparação com uma situação futura desejável. Hoje, esse instrumento vem sendo aperfeiçoado e, atualmente, conta com uma escala ordinal de cinco estágios: Existência de atividades individuais e pontuais (Estágio 1); Ações coletivas de curto prazo (Estágio 2); Ações 
sistêmicas de médio prazo com avaliação de metas pré-estabelecidas (Estágio 3); Ações de longo prazo com envolvimento de atores externos e avaliação comparativa com outras instituições (Estágio 4); e Ações de longo prazo com reflexo na sociedade, avaliação externa e repercussão de destaque entre as demais instituições (Estágio 5). Portanto, cada estágio é uma descrição verbal de um possível estado em que a instituição avaliada está a respeito de um dado critério. Um determinado estágio somente é alcançado se as fases anteriores forem atingidas em sua plenitude, pois todas as etapas de um critério são destinadas a serem cumulativas (BRANDLI et al., 2012).

Por fim, os resultados obtidos na presente pesquisa serão apresentados à comunidade universitária e às diferentes Comissões Temáticas empenhadas na elaboração do novo PDI da IES.

\section{Quadro 1: Síntese descritiva das diferentes dimensões de uma Universidade Sustentável}

\begin{tabular}{|c|c|}
\hline Dimensão & Descrição \\
\hline Educação & $\begin{array}{l}\text { Inclui proposições relativas à presença de tópicos em sustentabilidade } \\
\text { dentro do currículo, desenvolvimento de habilidades, cursos e } \\
\text { programas sobre desenvolvimento sustentável, revisão curricular e } \\
\text { programas de formação de professores. }\end{array}$ \\
\hline Pesquisa & $\begin{array}{l}\text { Refere-se à existência de estruturas e apoio financeiro para a produção } \\
\text { de conhecimento e tecnologias sobre a sustentabilidade, publicação, } \\
\text { patentes e reconhecimento internacional, e adoção de processos de } \\
\text { pensamento complexo, transdisciplinar, holístico. }\end{array}$ \\
\hline Operações no Campus & $\begin{array}{l}\text { Retrata a presença da sustentabilidade no funcionamento diário da } \\
\text { universidade, incluindo a eficiência do uso de recursos e o } \\
\text { gerenciamento de água, energia, resíduos, gases do efeito estufa, } \\
\text { transporte e acessibilidade, equidade, diversidade e acesso a alimentos } \\
\text { de qualidade. }\end{array}$ \\
\hline Extensão & $\begin{array}{l}\text { São ações relacionadas à integração da IES com a sociedade, incluindo } \\
\text { outras universidades, governos, empresas, escolas, ONGs e a } \\
\text { comunidade local. Somam-se os programas de intercâmbio para } \\
\text { estudantes no campo do desenvolvimento sustentável e a realização de } \\
\text { eventos abertos sobre o assunto. }\end{array}$ \\
\hline $\begin{array}{l}\text { Experiências no } \\
\text { Campus }\end{array}$ & $\begin{array}{l}\text { Retrata a existência de grupos de trabalho e outras práticas sustentáveis } \\
\text { entre alunos, professores e funcionários. Indica a presença cotidiana da } \\
\text { preocupação com a sustentabilidade dentro da comunidade acadêmica. }\end{array}$ \\
\hline Quadro Institucional & $\begin{array}{l}\text { Visto como um indicador do compromisso da instituição com a } \\
\text { sustentabilidade, fortalecendo sua presença nas políticas, missões, } \\
\text { declarações e outros documentos oficiais. }\end{array}$ \\
\hline $\begin{array}{l}\text { Avaliação e } \\
\text { Comunicação }\end{array}$ & $\begin{array}{l}\text { Avalia e relata o desempenho da sustentabilidade universitária, com } \\
\text { implicações na implantação dos sistemas de gestão ambiental, entre } \\
\text { vários que podem estar disponíveis, bem como a divulgação interna e } \\
\text { externa dos resultados desse monitoramento. Ranking (nacional e } \\
\text { internacional) de sustentabilidade da IES. }\end{array}$ \\
\hline
\end{tabular}

Fonte: Adaptado de Lozano et al. (2015) e Bizerril et al. (2018).

\section{METODOLOGIA}

Inicialmente, para a análise documental, adotou-se a análise de conteúdo, respeitando as fases de pré-análise, exploração do material e o tratamento dos resultados, incluindo a interpretação (BARDIN, 1977). Na pré-análise, optou-se pela escolha das três últimas versões do PDI (2008-2013, 2010-2014 e 2015-2019), considerando que esses documentos deveriam conter diretrizes básicas a uma universidade que se pretende ser sustentável. Considerou-se a hipótese de uma crescente preocupação histórica com a sustentabilidade nos campi da IES. A 
frequência das palavras-chave "meio ambiente", "sustentabilidade" e "sustentável" foi adotada enquanto indicador, por considerá-las essenciais em documentos de uma Universidade Sustentável.

$\mathrm{Na}$ fase de exploração do material, foi organizada uma lista com trechos e frases de ocorrência de cada palavra, permitindo uma visão sistematizada e a categorização dos diferentes sentidos. Por fim, o tratamento dos dados e a interpretação foram completados por uma reflexão das diretrizes ambientais contidas nos documentos. Isso permitiu ampliar a visão sobre os rumos das políticas institucionais para a gestão ambiental da IES. A análise quantitativa da frequência das palavras escolhidas foi complementada por uma representação gráfica (nuvem de palavras) para cada versão do PDI, considerando apenas as 30 palavras mais frequentes. Utilizou-se a plataforma livre, online, Wordcloud.com.

De forma complementar, a reflexão considerou o projeto de extensão "Papo de Academia", devidamente cadastrado e executado entre agosto e novembro de 2017, aberto à comunidade universitária. Foram previamente definidos cinco temas $e$ os respectivos palestrantes conhecedores dos problemas locais, os quais conduziram suas reflexões e promoveram debates com o público pelo período de duas horas. Realizou-se a divulgação em mídias e aplicativos sociais, mas também com auxílio de cartazes em pontos estratégicos no campus Sede. A inscrição foi gratuita e ocorreu pela internet. As discussões foram sistematizadas, consolidando, assim, extratos dos apontamentos de cada debate, que poderiam servir ao planejamento ambiental à própria IES e ao entorno imediato. Foram oferecidos certificados aos participantes que obtiveram mais de $75 \%$ de presença aos debates.

Neste trabalho, os extratos serviram de material para análise no presente estudo, sendo possível organizar os principais conteúdos discutidos ao longo da atividade de extensão e possíveis apontamentos à gestão local/regional.

Finalmente, as informações colhidas foram confrontadas com a descrição verbal dos cinco estágios previstos no instrumento AISHE (ROORDA, 2001), sendo possível definir o provável estado de sustentabilidade da IES. Contudo, o enfoque reflexivo considerou 0 contexto do Campus Sede da IES, o maior entre os seis campi, e onde funcionam dois centros de ensino: Centro de Ciências Exatas e Tecnológicas (CETEC); e o Centro de Ciências Agrárias, Ambientais e Biológicas (CCAAB).

\section{RESULTADOS E DISCUSSÃO}

A ambientalização nas universidades é considerada um dos caminhos mais indicados para alcançar a sustentabilidade. Acredita-se que isso acontecerá por diversos motivos condutores, convergentes e simultâneos; alguns internos (iniciativas docentes e discentes, filosofia da praxis curricular, apoio institucional dos tomadores de decisão e de uma política institucional) e outros externos (pressão da mídia e da opinião pública por melhor contextualização local/regional e apontamento de soluções e experiências que envolvam a sociedade civil) (MARCOMIM; SILVA, 2009).

É relevante destacar que, nesse campo de múltiplos interesses, a ambientalização corre riscos de tornar-se um simples substantivo abstrato, um neologismo, carregada de uma concepção utilitária que visa a garantir a continuidade de um sistema de produção e acumulação do capital, através da racionalização da exploração e do consumo de recursos naturais e a busca pelo desenvolvimento sustentável do sistema (OLIVEIRA et al., 2007).

O empenho institucional da equipe gestora de uma universidade pode ser também constatado por meio de ações executadas ou previstas no principal documento balizador de diretrizes gerais, princípios, valores e modelo de gestão de uma IES - o Plano de Desenvolvimento Institucional. Afinal, esse documento determina a missão, metas, objetivos, estratégias, diretrizes pedagógicas e ambientais que orientam as ações, a estrutura organizacional e atividades que subsidiarão 0 desenvolvimento de uma instituição de ensino (BILERT; LINGNAU; OLIVEIRA, 2014). Então, é esperado observar no PDI apontamentos ligados ao enfoque principal deste trabalho - a sustentabilidade.

O primeiro esforço analítico deste documento considerou a frequência das seguintes palavraschave: sustentabilidade, sustentável e meio ambiente. Constatou-se, curiosamente, que na primeira versão do PDI (com 50 páginas) apenas a palavra meio ambiente (1) esteva representada. A segunda versão (com 196 páginas) mostrou-se bem mais robusta, com destaque para a 
frequência da palavra sustentável (15), seguida de meio ambiente (10) e sustentabilidade (07). Por fim, a terceira versão (com 121 páginas) apresentou redução desproporcional dessas frequências: sustentável (4), sustentabilidade (2), e meio ambiente (1).

Complementando a análise quantitativa, a nuvem de palavras produzida para cada versão do PDI demonstrou que essas palavras-chave nem mesmo figuraram entre as 30 mais frequentes (Figura 2). Portanto, definitivamente, essa situação no principal documento institucional não inspira otimismo imediato na busca por uma universidade sustentável, pois, enquanto princípio institucional, a temática ainda aparece de forma isolada, sem uma Agenda Ambiental Institucional consolidada.
Denota-se, apesar de alguma variação entre as três versões, que os documentos estão preocupados em projetar a própria instituição (UFRB) e a importância do seu principal instrumento (PDI), além de reconhecer o tripé macrofuncional (pesquisa, ensino e extensão) e sua relação com aspectos sociais. Destaca-se que a palavra "desenvolvimento" somente esteve pronunciada nas versões mais recentes (Figura 2).

Ainda mais importantes são os sentidos e os contextos com que as palavras-chave foram apresentadas nas diferentes versões do PDI, além de uma reflexão sobre as diretrizes previstas nos documentos.

Figura 2: Nuvem de palavras das três diferentes versões do PDI

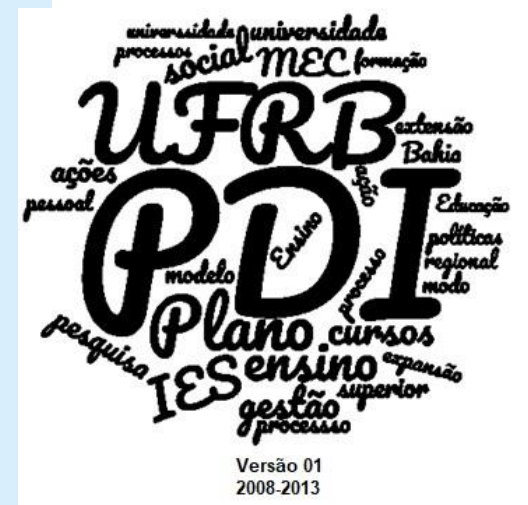

Fonte: Produção dos próprios autores.

A palavra "sustentável", por exemplo, foi fortemente adotada para adjetivar ora 0 desenvolvimento, ora o crescimento desejável; mas também adjetivar o planejamento do espaço físico e do Plano de Logística previsto no PDI vigente.

Há forte crítica reflexiva às características e limites do desenvolvimento sustentável, à sua crença ilimitada no potencial tecnológico, à valorização de experiências exógenas e apartadas do contexto local, e à defesa de um mercado sem regulações, demonstrando que, muitas vezes, esse termo pode induzir a um sentido ou ação sem poder de transformação social (LAYRARGUES, 1997). Talvez, por isso, devesse ser ponderado enquanto "princípio estatutário" da IES.

Vale destacar que o CCAAB e o CETEC representam um conjunto de habilidades $\mathrm{e}$ competências de interesse imediato do capital. Isso é especialmente preocupante em momentos de crise econômica e sucateamento do ensino superior, quando a própria comunidade acadêmica passa a defender interesses mercadológicos em função de sua própria sobrevivência e manutenção de seu funcionamento. A própria IES assumiu que "a produção do crescimento econômico-sustentável é um dos objetivos orientadores da política de pesquisa da UFRB" (PDI 2010-2014) (UFRB, 2009, p. 45). Entre os 834 docentes da IES, o CCAAB (163 docentes) e o CETEC (125 docentes) despontaram com 08 entre 14 atividades de consultoria registradas na universidade em 2017. Esses exemplos refletem nossa preocupação com os significados e contextos de uso dessas palavras no principal documento estruturante da universidade. 
Por sua vez, o sentido da palavra "sustentabilidade" foi quase que exclusivamente associado à dimensão financeira, obrigatoriamente considerada no processo de autoavaliação institucional e condicionante da expansão da universidade, mediante dotação orçamentária prevista na Lei Orçamentária Anual (LOA). Em menor escala, a sustentabilidade também foi adotada enquanto conceito administrativo, prática ou diretriz dos projetos de urbanização, ocupação, edificação e demais estruturas físicas. O termo "sustentabilidade" é bastante maleável e também pode representar a capacidade de um sistema manter-se em funcionamento, apesar da existência de tensores.

Constatou-se profusão de sentidos dado ao termo "meio ambiente", especialmente no PDI 2010-2014. O termo foi apontado enquanto fonte de indicadores necessários ao processo de autoavaliação; até mesmo por se tratar, naquele momento, de uma dimensão obrigatória da responsabilidade social institucional, culminando na criação de dois núcleos: Núcleo de Meio Ambiente e Núcleo de Gestão de Extensão em Saúde e Meio Ambiente. Embora complementares, em nossa análise, passaram a figurar de forma autônoma, subordinados a diferentes superintendências e coordenadorias, explicitadas na própria estrutura organizacional da IES. Outro aspecto relevante é a importância do meio ambiente enquanto justificativa ao próprio surgimento da IES, sua concepção de multicampia e a construção de sua identidade institucional, inclusive enquanto princípio orientador dos currículos de graduação.

Também merecem destaques algumas diretrizes induzidas pelos planos de desenvolvimento institucional que não garantiram a sua efetiva execução e consequente avanço da sustentabilidade institucional na história recente da IES.

A primeira versão do PDI, por exemplo, tentou fomentar a construção de um Plano Diretor em cada campus para balizar a ocupação e definição das áreas de preservação, implantação de jardins e estabelecimento de reserva legal. Propôs índice mínimo de área verde, plano de arborização, sistema de gestão de resíduos e programas de racionalização/redução de energia, água e materiais; mas não definiu ações prioritárias e prazos para consecução do Plano Diretor. Ressalta-se que, ainda hoje, o CCAAB foi o único centro de ensino a ter elaborado o Plano Diretor.

A segunda versão do PDI valorizou diretrizes curriculares dos diferentes cursos e políticas institucionais de gestão ambiental. Sugeriu a construção do Plano de Desenvolvimento Físico e Ambiental (PDFA) articulado ao PDI, tendo por pressupostos a preservação e o desenvolvimento sustentável do patrimônio fundiário e suas edificações. Naquele momento, havia preocupação com a questão fundiária da própria IES, mas as ações e programas para ampliação da consciência sustentável foram ausentes. Sugeriu, ainda, a criação de um Plano Ambiental geral da instituição, que infelizmente não foi elaborado.

Por sua vez, o PDI vigente apresenta deficiências na abordagem das questões ambientais, pois trata dos termos "ambiental" e "ambiente" de forma esporádica e sem menção de estratégias e ações, ou seja, historicamente, permanece a postura institucional de pensar o meio ambiente, mas sem mobilização organizacional e definição de metas para a efetivação de ações vinculadas a este fim.

Interessada em promover a sustentabilidade, uma Universidade Sustentável deve assumir seu compromisso, além das atribuições e responsabilidades legais, de envolver-se nas diferentes dimensões, as quais serão agora detalhadas, especialmente na sede da instituição.

\subsection{Educação}

A dimensão "Educação" na sustentabilidade universitária merece destaque especial no contexto do CCAAB e do CETEC, dois centros de ensino localizados no campus sede da universidade (o maior deles). Ambos agregam a maioria dos cursos de engenharia da IES e juntos reúnem mais de 650 componentes curriculares ofertados (obrigatórios e optativos), semestralmente, aos estudantes da graduação. Apenas sete componentes curriculares (nem sempre obrigatórios) abordam explicitamente os conteúdos de educação ambiental, sustentabilidade, ética e gestão ambiental.

Nesses centros de ensino, por exemplo, a educação ambiental é componente obrigatório apenas ao curso de licenciatura em biologia, sendo optativo aos demais estudantes. Obviamente que a criação de componentes curriculares não é a única estratégia de curricularização da temática ambiental. Cada 
componente curricular pode incorporar em seu ementário conteúdos teóricos e práticos destinados a uma discussão mais aplicada ao contexto local/regional. A criação de projetos integrados de longo prazo entre diferentes componentes e cursos também representa uma alternativa promissora. Também parece moderno, sempre que possível, diminuir entraves curriculares como os pré-requisitos.

Aparentemente, a ambientalização curricular dos cursos de graduação do CCAAB e CETEC se aproxima do "Modelo Multidisciplinar", em que a temática ambiental está dispersa em disciplinas isoladas, com nenhum ou pouco nível de coordenação entre elas (KITZMANN; ASMUS, 2012). Tal afirmativa é reforçada em estudo que analisou projetos pedagógicos de diferentes cursos de engenharia sediados na Bahia (MIRANDA; DELGADO-MENDEZ; MENEZES, 2014). Os autores constataram que, raramente, os cursos de engenharia oferecem mais que 3,5\% de carga horária total para tratar temas diretamente dedicados à questão ambiental, destinando apenas $1,6 \%$ de carga horária entre os componentes de natureza obrigatória.

Diversos estudos em países de língua portuguesa (PLP) apontam que a dimensão "Educação" é aquela com o maior número de contribuições à sustentabilidade; incluindo a defesa pela inserção curricular de estratégias e valores como: dignidade; justiça; liberdade; avaliação ambiental estratégica; o papel da universidade no fortalecimento da sociedade; adoção de sistemas de gestão da aprendizagem; e grupos colaborativos de diferentes cursos (BIZERRIL et al., 2018). Por isso, acredita-se que, imediatamente, tal situação deverá receber atenção institucional, principalmente agora que os cursos de graduação da IES estão concluindo a revisão de seus projetos pedagógicos.

\subsection{Extensão}

Constatou-se, em 2017, crescimento de $78 \%$ no número de ações extensionistas quando comparado a 2013 (início do monitoramento) (UFRB, 2018). Em 2017, foram cadastradas 624 ações de extensão (cursos, eventos, projetos, programas, prestação de consultorias) pelos sete centros de ensino (juntos, CCAAB e CETEC cadastraram 166 atividades). $A$ área "meio ambiente", com 34 ações, figurou com um dos menores números de propostas entre as oito áreas possíveis (área educação teve 227 ações).
Há boa interação da IES com diferentes setores da sociedade (públicos e privados), com forte inserção no contexto local/regional, mas o aspecto negativo está relacionado ao pequeno número de publicações derivadas das ações realizadas em 2017 (apenas 02 publicações). Embora seja necessário algum tempo de sistematização, análise e reflexão dos resultados, esse é um panorama comum entre as universidades brasileiras, que ainda carecem de maior divulgação dessas ações, especialmente no cenário internacional (BIZERRIL et al., 2018).

É igualmente importante destacar que o Plano Nacional de Educação (2014-2024) impôs a obrigatoriedade da curricularização da extensão em todos os cursos de graduação das IES brasileiras. Acredita-se que isso promoverá inúmeros ajustes e um repensar das concepções e práticas extensionistas. Portanto, essa ação terá reflexos não apenas na dimensão educação, mas, principalmente, no número de ações de extensão a serem cadastradas. Além do mais, a proposição de uma resolução interna representará, em última análise, uma nova diretriz institucional.

\subsection{Operações no campus}

O Recôncavo enfrenta problemas de conflito por água e energia, a exemplo dos transtornos e manifestações que ocorrem no baixo curso do rio Paraguaçu, onde está localizado o "Complexo de Pedra do Cavalo". Per se, a IES deveria oferecer exemplos de boas práticas à sociedade, mas a sustentabilidade universitária também depende de ações concretas transformadoras do espaço físico, dentro ou fora do campus, como em seu entorno imediato.

Dados oficiais obtidos junto ao Núcleo de Logística Sustentável da IES demonstram que, ao longo de 2016, somente a Sede consumiu 42.145 $\mathrm{m}^{3}$ de água (média de $3.512 \mathrm{~m}^{3} / \mathrm{mês}$ ). No mesmo período, o valor líquido (consumo + iluminação pública + multa e juros) gasto para pagamento de energia elétrica neste mesmo campus foi de $R \$$ 1.860.941,31 (média $R \$ 155.078,44 / \mathrm{mês}$ ).

Recentemente, a administração central, por meio de portarias específicas, criou Grupos de Trabalhos (GTs) para pensar soluções e diminuir - consumo de água, energia e melhorias na comunicação. Aparentemente, o GT Água obteve maiores avanços, com um robusto diagnóstico no campus Sede, como mapeamento da rede hidráulica, localização de hidrômetros, 
identificação dos pontos de vazamento, poços ativos e inativos, estratégias adotadas de abastecimento pelos carros transportadores, condições operacionais dos reservatórios e estratégias de manutenção corretiva. Devido à própria relevância histórica e expertise técnica existente na Sede da IES, a situação dessa dimensão deveria estar mais avançada. De qualquer forma, agora, estão sendo pensadas estratégias operacionais para enfrentamento desse problema. É sugerido à universidade adotar práticas (baixo, médio e alto custo) de manutenção e diminuição de consumo de água e energia, algumas bem simples (MEC, 2015).

Comparativamente, outra IES no nordeste brasileiro, com 19 mil estudantes (graduação e pós-graduação) e 3322 servidores (técnicos e docentes), em um sistema de multicampia (sete campi) adotou o modelo de gestão do Programa Agenda Ambiental na Administração Pública (A3P), para avaliar práticas de gestão ambiental (ARAÚJO; FREITAS; ROCHA, 2017). O Eixo 6, que trata das estratégias e ações para minimizar impactos das construções, promover economia de recursos naturais e melhoria do ambiente construído (iluminação e ventilação natural e acessibilidade), teve até $86 \%$ de adesão em dois campi e $57 \%$ na sede, portanto, em situação bem mais avançada que a IES em análise no presente estudo.

É importante destacar que são inúmeras as obras inacabadas nas universidades públicas e isso tem sérias implicações ao processo de sustentabilidade ambiental e ao próprio desejo institucional por realizar ações proativas e planejadas, de longo prazo, destinadas a melhorar a sustentabilidade. Soma-se a existência de uma infraestrutura predial mais antiga, que exige constante manutenção e adequação de sua rede elétrica e hidráulica. Outra preocupação adicional relaciona-se a pouca atenção dada aos cenários futuros de mudanças climáticas e aquecimento global, que demandarão novos materiais e concepções arquitetônicas, ambientalmente confortáveis e inteligentes.

\subsection{Pesquisa}

Em 2017, foram efetivamente cadastrados 222 projetos de pesquisa vinculados aos sete centros de ensino (CCAAB e CETEC registraram 118). Foram 282 bolsas distribuídas entre os diferentes programas de iniciação científica na
IES e pelo menos $R \$ 256.430,00$ (PROAP + PNPD) compartilhados com os programas stricto sensu de pós-graduação, quase todos funcionando na sede. Atualmente, existem 183 grupos de pesquisa registrados no Diretório de Grupos de Pesquisa do CNPq devidamente certificados pela instituição. Também foram protocolados sete produtos tecnológicos, protegidos, junto à Coordenação de Criação e Inovação (CINOVA) (UFRB, 2018).

Aparentemente, observa-se forte concentração de esforços das ações de pesquisa na sede da IES, especialmente no CCAAB. Isso reflete o próprio movimento histórico de criação da IES, que também acabou reunindo as melhores condições para a criação dos programas de pós-graduação. Embora exista um monitoramento do número de projetos em função das áreas de conhecimento, é difícil afirmar quais ações efetivamente estão relacionadas à sustentabilidade ambiental, por se tratar de um tema que pode permear diferentes áreas de conhecimento (agrárias, biológicas, ciências da terra, saúde...). Também, há uma discussão relevante quanto aos critérios mais equilibrados para distribuição de bolsas para cada centro de ensino. Por tudo isso, parece oportuno induzir linhas de pesquisa específicas para enfrentar problemas de sustentabilidade dentro da própria IES, inclusive na adequação de procedimentos no campus.

Nos países de língua portuguesa (PLP), por exemplo, constatou-se recente aumento da produção científica na área de sustentabilidade, embora concentrada em poucas instituições, de modo que as regiões com maiores demandas sociais e ambientais permanecem com produção limitada (BIZERRIL et al., 2018). O trabalho de revisão desses autores também relatou a existência de apenas três estudos relacionando a pesquisa com os problemas de gestão ambiental nas IES. Ainda assim, as dimensões relativas à pesquisa, educação, avaliação e comunicação foram aquelas que receberam as principais contribuições nos PLP.

\subsection{Avaliação e Comunicação}

No Brasil, as IES são obrigadas a apresentar relatórios de gestão aos órgãos de controle interno e externo para prestação de contas anual de suas ações, nos termos do Art. 70 da Constituição Federal e balizadas por Instruções Normativas do Tribunal de Contas da União 
(TCU). Portanto, em certa medida, esses relatórios tornam possível a coleta de indicadores das diferentes dimensões de uma universidade sustentável, oferecendo um panorama de todas as funcionalidades e responsabilidades institucionais (pesquisa, ensino, extensão, finanças...), incluindo um tópico específico "Gestão Ambiental e Sustentabilidade".

Sabe-se, por exemplo, que a IES analisada não adota a Agenda Ambiental da Administração Pública (A3P), embora tenha elaborado um Plano de Logística Sustentável visando a adotar práticas de racionalização e sustentabilidade das despesas da instituição, além de envolver a comunidade acadêmica e uma cultura da sustentabilidade. Também, realizou a primeira Chamada Pública (Compra Institucional) do Programa de Aquisição de Alimentos (PAA) para suprir demandas regulares do Restaurante Universitário localizado na sede da instituição. Os resíduos recicláveis, coletados em todos os campi, são destinados a duas associações regionais mediante Termo de Cooperação Técnica. Esse documento aponta, ainda, que os servidores carecem de visão crítica do assunto, mesmo para iniciativas corriqueiras (desligar os interruptores, aparelhos de ar condicionado e monitores dos computadores quando saem da sala etc.). Por fim, se reconhece também "uma necessidade de incluir a sustentabilidade ambiental na Agenda da Instituição, que servirá de fio condutor por onde todas as ações da Universidade deverão passar" (UFRB, 2018, p. 97).

Esses relatórios, ainda que elaborados por força da lei, representam uma esperança pelo uso de indicadores necessários à gestão e ao planejamento ambiental da instituição. Todavia, a comunicação segue sendo um desafio, já que os relatórios globais e setoriais, quando publicados, são exclusivamente disponibilizados no portal da universidade ou no site das respectivas próreitorias, sem um debate mais amplo com a comunidade. Esse fato é relevante, pois setores da comunidade acadêmica não estão habituados a consultar esses documentos.

Tal afirmativa é endossada por um estudo que avaliou a observância das diretrizes ambientais em cursos de graduação de uma IES no Rio Grande do Sul. Enquanto coordenadores acreditam que as diretrizes ambientais se façam presentes em alguns casos, professores e discentes foram unânimes em dizer que estas não estão sendo observadas, refletindo a falta de uma política e de um sistema de gestão ambiental organizados que fortaleçam as diretrizes e tornem a sua observância algo natural à comunidade acadêmica (BRANDLI et al., 2012). Na Europa, pesquisa endereçada eletronicamente a 800 pessoas (208 questões, abertas e fechadas) obteve 87 respondentes $(10,88 \%)$ pertencentes a 70 IES (LOZANO et al., 2015). Os resultados apontaram nível considerável de reconhecimento da implantação do desenvolvimento sustentável em todas as dimensões das IES, com exceção da dimensão "Avaliação e Comunicação".

Sugere-se oferecer maior visibilidade aos documentos de gestão e indicadores de sustentabilidade a toda comunidade acadêmica a partir de reuniões setoriais em cada campus da IES. Essa seria uma boa oportunidade para realizar o Seminário Universidade Sustentável e ampliar o compromisso institucional, inserindo o evento no calendário acadêmico.

\subsection{Experiências no campus}

Questões emblemáticas na sede sugerem ser essa a dimensão de maior visibilidade e discussão na IES. Destaca-se o mapeamento de 43 nascentes dentro do campus (quase todas dentro da microbacia do Riacho do Machado). No entorno das nascentes, são observados o pastejo de bovinos e equinos, a retirada de madeira e o acúmulo de lixo. A cobertura vegetal está bastante alterada. Pelo menos 25 famílias vivem no entorno da área e as doenças por falta de saneamento são frequentes (DOURADO et al., 2009). Os autores sugeriram atividades educativas e a necessidade de criação de novas tecnologias de produção a partir do intercâmbio entre engenheiros agrônomos e agricultores, visando ao aprimoramento das atividades produtivas agrícolas e a garantir a sobrevivência e revitalização do riacho.

Também, foram sugeridas ações educativas e a ampliação de esforços da comunidade acadêmica, moradores/as e do setor público para amenizar a situação de degradação dessas nascentes, já que é flagrante o descumprimento do Novo Código Florestal em relação à proteção e conservação das áreas de preservação permanente (PINTO et al., 2017).

Boa parte dessas informações técnicas foi gerada a partir de exercícios em diferentes componentes curriculares e trabalhos monográficos. Seminários internos foram 
organizados e realizados pelos discentes, além de denúncias encaminhadas ao Ministério Público Federal, gerando debates na IES e demais instituições envolvidas (públicas e privadas). Esse esforço pressionou a administração central pela criação da Área de Proteção Experimental (APEX) do Córrego do Machado (Portaria no 587/2017) (UFRB, 2017), com um conselho legalmente constituído e encarregado de alavancar ações de planejamento. Há, inclusive, uma proposta de recuperação da APEX em três fases de ampliação.

A arborização do campus Sede e a revitalização do viveiro florestal foram outras ações emblemáticas. Com o apoio de docentes, pelo menos 80 estudantes se envolveram, voluntariamente, na reestruturação do viveiro, além da preparação de pelo menos 2000 mudas (frutíferas, ornamentais e arbóreas) e plantio de 650 indivíduos. Canteiros foram reorganizados, incluindo a manutenção da cobertura e o planejamento de estruturas físicas do viveiro. Diferentes projetos foram, então, aglutinados ao "Programa Arborizar", elaborado e cadastrado por discentes enquanto projeto de extensão. Estudos monográficos também fizeram a proposição de transformar o viveiro florestal em um Viveiro Didático, de modo a criar mais um espaço educador para a cidade. Aparentemente, várias dessas ações estão paralisadas, em função do forte contingenciamento de recursos para as IES.

Como mencionado, essas ações foram emblemáticas e tiveram visibilidade dentro da Sede, como demonstra o resultado obtido na atividade de extensão conduzida pelo PET Mata Atlântica, possibilitando sistematizar preocupações relevantes ao contexto local/regional (Tabela 1). Foram destacados, suscintamente, o Projeto Arborizar; a criação da APEX e seu conselho; e o mapeamento/caracterização das nascentes no interior do campus Sede. Também, foram observados esforços para inserção da IES no processo de organização da gestão municipal ambiental.

Foram registradas 173 inscrições neste projeto de extensão coordenado pelo PET Mata Atlântica, mas somente 75 inscritos participaram de algum debate. Ao final, apenas 23 estudantes atenderam a exigência mínima de $75 \%$ de participação aos debates. Isso demonstra que o esforço para envolvimento da comunidade universitária não depende apenas de uma boa divulgação e oferta de certificados aos participantes. Embora tenha sido ponderado o horário das palestras e o acúmulo de atividades acadêmicas dentro do período letivo (que talvez tenha contribuído para o esvaziamento da atividade), os dados de frequência dos participantes apontam para a necessidade de revisão das estratégias, de modo a ampliar a militância ambiental na comunidade acadêmica e o conjunto de problemas reais a serem debatidos neste espaço de convivência cotidiana que é a universidade.

Em linhas gerais, a participação ativa e informada de diferentes atores em processos democráticos amplia as chances de eficácia da gestão e da sustentabilidade ambiental. A cultura da participação é propícia à transição para Universidades Sustentáveis (DISTERHEFT et al., 2015).

Finalmente, falta apontar a situação geral da sustentabilidade na sede da IES analisada. Ainda que preliminar e superficial, o conjunto de informações colhidas e analisadas permitiu constatar, por exemplo, a existência de projetos coletivos, mas sem uma continuidade de longo prazo e metas quantificáveis, típicas do estágio 2 na escala AISHE. Todavia, isso não significa que a IES tenha superado, plenamente, o estágio 1 (com existência de atividades individuais e pontuais). Portanto, acreditamos que a sede da IES esteja em situação intermediária entre esses dois níveis de sustentabilidade.

Embora não tenha sido registrado um sistema de pontuação, a opção pela escala AISHE demonstra caminhos a serem trilhados para alcançarmos a sustentabilidade universitária. Ela pode ser usada para incluir elementos da sustentabilidade nas diferentes dimensões analisadas, para avaliar a política dos anos pretéritos (FERREIRA; LOPES; MORAIS, 2006) ou propor apontamentos futuros (BRANDLI et al., 2012). Segundo os autores, os resultados também possibilitam a construção de relatórios e comunicações para informar a sociedade quanto ao progresso de um plano ambiental da instituição, demonstrar sua preocupação com o meio ambiente, e ajudar a manter uma base de dados sobre programas de gestão ambiental.

Neste momento, as dimensões avaliação e comunicação, operações no campus e experiências no campus mostram-se com maior projeção dentro da comunidade acadêmica. Todavia, é imperativo buscar avanços no quadro 
institucional, uma vez que a IES não possui Plano de Gestão Ambiental e apenas um único Centro de Ensino (CCAAB) tenha concluído o seu Plano Diretor. Ainda assim, não parece existir uma visão integrada já que CCAAB e CETEC compartilham espaços, recursos e enfrentam problemas semelhantes no mesmo campus, demonstrando a necessidade de colaboração na produção de um único documento.
Urge instigar os estudantes a pesquisar os problemas socioambientais da sua própria IES. Esse seria um passo inicial para a geração de dados e estruturação de um plano de gestão ambiental. Isso é corroborado pela opinião de Santos e Sato (1996) sobre a necessidade de se compreender a academia enquanto um grande laboratório de convivência, para gerar condições concretas ao contexto regional, sem perder a dimensão mais complexa do pensamento.

\section{Tabela 1: Resultado da sistematização dos principais tópicos abordados durante o ciclo de debates conduzido pelo PET Mata Atlântica em 2017}

\begin{tabular}{|c|c|}
\hline Título do Debate / Tema & Principais Pontos Abordados \\
\hline $\begin{array}{l}\text { O contexto da Mata } \\
\text { Atlântica no Recôncavo } \\
\text { e a necessidade de } \\
\text { intervenção }\end{array}$ & $\begin{array}{l}\text { Características do Bioma Mata Atlântica (florística, distribuição, regime } \\
\text { pluviométrico, endemismo). Panorama do desflorestamento (Brasil, } \\
\text { Bahia e Recôncavo). Cobertura do solo no Recôncavo e dificuldades } \\
\text { metodológicas. Restauração ecológica enquanto parte da solução. } \\
\text { Estratégias e experiências de conservação: sistemas agroflorestais } \\
\text { (SAFs). Questionar a agricultura deletéria. Cadastro estadual florestal } \\
\text { (CEFIR), agricultura familiar e o novo Código Florestal. }\end{array}$ \\
\hline $\begin{array}{l}\text { É preciso avançar com } \\
\text { arborização urbana em } \\
\text { nossos municípios }\end{array}$ & $\begin{array}{l}\text { O Projeto Arborizar e o efetivo plantio de } 650 \text { mudas no campus de } \\
\text { Cruz das Almas. Os benefícios da arborização e a necessidade de } \\
\text { conscientização das pessoas e instituições. Exemplos de arborização } \\
\text { no Brasil e no mundo. Ações equivocadas de arborização, } \\
\text { manutenção e podas. O cenário de Cruz das Almas e a falta de } \\
\text { planejamento. Necessidade de envolvimento discente com a pesquisa } \\
\text { em arborização urbana. Entraves políticos à arborização. }\end{array}$ \\
\hline $\begin{array}{l}\text { As ações do Projeto } \\
\text { Arborizar/UFRB: análise } \\
\text { das oportunidades e } \\
\text { desafios do primeiro ano } \\
\text { de implementação }\end{array}$ & $\begin{array}{l}\text { Motivações do Projeto Arborizar (baixo sombreamento no campus). As } \\
\text { etapas do projeto e o apoio do Núcleo de Meio Ambiente (NUMAM). } \\
\text { Estratégias para captação de recursos financeiros e materiais. A } \\
\text { organização interna dos grupos discentes. Produção de mudas de } \\
\text { espécies nativas e o Trote Ecológico. Produção de } 2000 \text { mudas. A } \\
\text { origem dos atuais projetos complementares e as experiências } \\
\text { pretéritas. }\end{array}$ \\
\hline $\begin{array}{l}\text { Experiências de gestão } \\
\text { ambiental municipal e } \\
\text { perspectivas para a } \\
\text { Área de Proteção } \\
\text { Experimental da UFRB }\end{array}$ & $\begin{array}{l}\text { Experiência de gestão ambiental municipal em Santa Inês-BA. A } \\
\text { construção de um Plano de Gestão Integrado entre as diferentes } \\
\text { secretarias municipais. Desafios observados no município de Santa } \\
\text { Inês. A criação da APEX e suas características, objetivos e parceiros. } \\
\text { A criação do Conselho Gestor e do Comitê Executivo da APEX. } \\
\text { Desafios do financiamento e a parceria com a Prefeitura Municipal. }\end{array}$ \\
\hline $\begin{array}{c}\text { Por uma Agenda } 21 \text { na } \\
\text { UFRB }\end{array}$ & $\begin{array}{l}\text { A sustentabilidade e o envolvimento institucional da IES. Experiências } \\
\text { de sustentabilidade universitária (captação de água, coleta de } \\
\text { resíduos etc). Conhecer os problemas e suas interações para pensar } \\
\text { soluções. Existência de } 43 \text { nascentes em } 1200 \text { ha do campus Cruz } \\
\text { das Almas. Proatividade discente. Entraves políticos no campus de } \\
\text { Cruz das Almas. Necessidade de visão sistêmica. }\end{array}$ \\
\hline
\end{tabular}

Fonte: PET Mata Atlântica/UFRB (Projeto Papo de Academia). 


\section{CONCLUSÃO}

A análise conduzida na sede da IES sugere um panorama atual que reflete posição intermediária entre os estágios 1 e 2 de sustentabilidade, ainda prevalecendo ações individuais e pontuais.

Apesar da boa intencionalidade, as diferentes versões do PDI da IES analisada demonstraram fragilidades para com as ações ambientais, prevalecendo a adjetivação do planejamento e a ausência de mobilização organizacional para atingir metas previstas. Neste momento, a IES caminha para a formulação do seu novo PDI, com metas previstas até 2030. A data é emblemática e seria sensato aderir aos 17 Objetivos do Desenvolvimento Sustentável 2030, que muito contribuiriam ao enfrentamento dos desafios à sustentabilidade universitária.

A ambientalização curricular na IES tem adotado o modelo multidisciplinar, com temáticas ambientais dispersas em disciplinas isoladas. Felizmente, há otimismo envolvido no presente momento dado ao processo de revisão dos projetos pedagógicos, incluindo a perspectiva da curricularização da extensão. Tais ações poderão promover maior coordenação de ações entre os diferentes componentes curriculares. Muitas ações são conduzidas na IES sem a devida valorização e comunicação e, por isso, acreditase que pequenos ajustes podem melhorar a sustentabilidade institucional frente à dimensão "avaliação e comunicação".

O atual panorama de sustentabilidade ambiental na sede da universidade reflete processo histórico que vai além da adoção estratégica da multicampia, pois incorporou parte da infraestrutura pregressa, portanto, um tipo de "passivo" a ser metabolizado (problemas fundiários e de uso da terra, estrutura e suficiência elétrica e hidráulica, arborização, entre outros). Esse conjunto de problemas representa 0 principal desafio a ser enfrentado pela IES nos anos vindouros, pois a comunidade universitária ampliará demandas por experiências e procedimentos sustentáveis no campus e no próprio contexto regional.

Urge, portanto, a estruturação de um plano de gestão ambiental para os diferentes campi. Algumas das ações em curso podem e devem ser incorporadas e motivadas, bem como o esforço pedagógico para incentivar pesquisas e ações dentro da própria universidade. A indução de linhas específicas de pesquisa e extensão pode ser uma estratégia interessante para alavancar o interesse pela solução de problemas reais da instituição.

Por fim, os desafios socioambientais existentes no Recôncavo da Bahia impõem à universidade a necessidade de adoção de medidas urgentes que possam sinalizar à sociedade (interna e externa) o tamanho de sua responsabilidade social. É preciso assumir seu protagonismo para além das demandas e exigências legais impostas pelos órgãos de controle, devendo definir seu modelo de desenvolvimento e metas de sustentabilidade a serem alcançadas.

\section{AGRADECIMENTOS}

Os autores agradecem ao Programa de Educação Tutorial da UFRB, à Pró-reitoria de Extensão e ao Centro de Ciências Agrárias, Ambientais e Biológicas pelo apoio incondicional na execução das atividades de extensão. Também agradecemos o Núcleo de Logística Sustentável pelo compartilhamento de dados e informações. Somos gratos, ainda, aos revisores que ofereceram sugestões valiosas ao aprimoramento do trabalho.

\section{REFERÊNCIAS}

ARAÚJO, S. M.; FREITAS, L. S.; ROCHA, V. S. G. Gestão ambiental: práticas sustentáveis nos campi de uma IFES. Reunir, Sousa, v. 7, n. 3, p. 36-50, set./dez. 2017.

BARDIN, L. Análise de conteúdo. Lisboa: Edições, 1977. 70p.

BILERT, V. S. S.; LINGNAU, R.; OLIVEIRA, M. R. A educação ambiental nas universidades públicas estaduais do Paraná: uma análise a partir dos documentos institucionais. Monografias Ambientais, Santa Maria, v. 13, n. 4, p. 3444-3452, set./dez. 2014

BIZERRIL, M.; ROSA, M. J.; CARVALHO, T. Universidades sustentáveis: uma discussão a partir do caso de uma universidade portuguesa. In: CONFERÊNCIA DA FORGES, 6., 2016, Campinas. Anais... Campinas-SP: UNICAMP, 2016. 12p.

Sustainability in higher education: a review of contributions from Portuguese speaking countries. Journal of Cleaner Production, Knoxville, v.171, p. 600-612, jan. 2018. 
BRANDLI, L. L.; FRANDOLOSO, M. A. L.; FRAGA, K. T.; VIEIRA, L. C.; PEREIRA, L. A. Avaliação da presença da sustentabilidade ambiental no ensino dos cursos de graduação da Universidade de Passo Fundo. Avaliação, Campinas; Sorocaba, v. 17, n. 2, p. 433454, jul. 2012.

BRASIL. Lei no 9.795 de 27 de abril de 1999. Institui a Política Nacional de Educação Ambiental. Diário Oficial [da] República Federativa do Brasil, Poder Executivo, Brasília, DF, 14 abr. 1999.

DAL MAGRO, C. B.; RAUSCH, R. B. Plano de desenvolvimento institucional de universidades federais brasileiras. Administração: Ensino e Pesquisa, Rio de Janeiro, v. 13, n. 3, p. 427-454, jul./ago./set. 2012.

DISTERHEFT, A.; CAEIRO, S.; AZEITEIRO, U. M.; LEAL FILHO, W. Sustainable universities: a study of critical success factors for participatory approaches. Journal of Cleaner Production, Knoxville, v. 106, p.11-21, nov. 2015.

DOURADO, C.; MOREIRA, G. C. M.; JESUS, J. A.; PINTO, F. C.; CERQUEIRA, B. S.; SAMPAIO, C. B. V. Avaliação de impactos socioambientais na Região da Microbacia do Ribeirão do Machado em Cruz das Almas - BA. Revista Brasileira de Agroecologia, Pelotas, v. 4, n. 2, p. 2928-2931, 2009.

FERREIRA, A. J. D.; LOPES, M. A. R.; MORAIS, J. P. $F$. Environmental management and audit schemes implementation as an educational tool for sustainability. Journal of Cleaner Production, Knoxville, v. 14, p. 973-982, 2006.

KITZMANN, D.; ASMUS, M. Ambientalização sistêmica: do currículo ao socioambiente. Currículo sem Fronteiras, v. 12, n. 1, p. 269-290, jan./abr. 2012.

LARA, P. T. R. Sustentabilidade em instituições de ensino superior. Monografias Ambientais, Santa Maria, v. 7; n. 7, p. 1646-1656, jun. 2012.

LAYRARGUES, P. P. Do ecodesenvolvimento ao desenvolvimento sustentável: evolução de um conceito? Proposta, Rio de Janeiro, v. 24, n. 71, p. 1-5, fev. 1997.

LOZANO, R.; CELEUMANS, K.; ALONSO-ALMEIDA, M.; HUISINGH, D.; LOZANO, F. J.; WAAS, T.; LAMBRECHTS, W.; LUKMAN, R.; HUGE, J. A review of commitment and implementation of sustainable development in higher education: results from a worldwide survey. Journal of Cleaner Production, Knoxville, v.108, p.1-18, dez. 2015.

MARCOMIM, F. E.; SILVA, A. D. V. A sustentabilidade no ensino superior brasileiro: alguns elementos a partir da prática de educação ambiental na universidade.
Contrapontos, Itajaí, v. 9, n. 2, p.104-117, mai./ago. 2009.

MEC - Ministério da Educação. Secretaria de Educação Continuada, Alfabetização, Diversidade e Inclusão. Diretoria de Políticas de Educação em Direitos Humanos e Cidadania; Coordenação-Geral de Educação Ambiental. Manual Escolas Sustentáveis. Brasília, 2013. Disponível em: http://pdeinterativo.mec.gov.br/escolasustentavel/manu ais/Manual_Escolas_Sustentaveis_v\%2026.06. 2013.pdf. Acesso em: 18 ago. 2015.

Resolução no 18, de 3 de setembro de 2014. Dispõe sobre a destinação de recursos financeiros, nos moldes operacionais e regulamentares do Programa Dinheiro Direto na Escola (PDDE), a escolas públicas da educação básica, a fim de favorecer a melhoria da qualidade de ensino e a promoção da sustentabilidade socioambiental nas unidades escolares. Brasília: CD/FNDE, 2014.

Desafio da Sustentabilidade. Coleção. Brasília: MEC, 2015. 40p.

MIRANDA, C. E.; DELGADO-MENDEZ, J. M.; MENEZES, J. A. S. Educação ambiental e suas implicações no ensino superior: o caso das escolas de engenharia em Salvador. In: RANGEL, S.; MAGALHÃES, T. C. (Org.). Reflexões sobre educação: uma visão multidisciplinar. Salvador: Quarteto, 2014. p. 93-107.

OLIVEIRA, H; FARIAS, C; PAVESI, A; CINQUETTI, H. Mapeamento da educação ambiental em instituições brasileiras de educação superior: elementos para políticas públicas. Brasília: Órgão Gestor da Política Nacional de Educação Ambiental (Série Documentos Técnicos no 12), 2007.

PINTO, D. L.; BARRETO, J. V. F. B; MENDES, L. C.; WATANABE, K.; SILVA e SILVA, C. Áreas de preservação permanente ameaçadas: o caso das nascentes da UFRB e comunidades limítrofes no âmbito do código florestal. In: FÓRUM INTERNACIONAL DE RESÍDUOS SÓLIDOS, 8., 2017, Curitiba. Anais... Curitiba-PR: UTFPR, 2017. 10p.

ROORDA, N. AISHE: Auditing Instrument for Sustainability in Higher Education. Dutch Foundation on Sustainable Higher Education and the Dutch Ministry of Environmental Affairs, Dutch, 2001. 119p.

SANTOS, J. E.; SATO, M. Universidade e ambientalismo: encontros não são despedidas. In: A contribuição da educação ambiental à esperança de Pandora. 3. ed. São Carlos: Rima, 1996. p. 31-49.

UFRB - UNIVERSIDADE FEDERAL DO RECÔNCAVO DA BAHIA. Portaria n. 587, de 19 de julho de 2017. 
Cria a Área de Proteção Experimental - APEX. Cruz das Almas-BA, 2017.

\section{. Relatório de Gestão do Exercício de 2017.}

Cruz das Almas-BA: UFRB, 2018. Disponível em:
$<$ www.ufrb.edu.br/proplan/documentos/category/8relatorio-de-gestao?download $=81$ :relatorio-de-gestao2017.> Acesso em: 10 set. 2018. 